\title{
Echocardiographic Study on Hypertrophic Cardiomyopathy
}

\author{
Hironori Toshima, M.D., Yoshinori Koga, M.D., Shunpo Uemura, \\ M.D., Juzabu Zinnouchi, M.D., Noboru Kimura, M.D., and \\ Shigeo Nakakura, M.D.*
}

\section{SUMMARY}

Echocardiographic study was performed on 21 cases with hypertrophic cardiomyopathy (HCM), 10 obstructive and 11 nonobstructive.

Asymmetric septal hypertrophy was demonstrated in both obstructive and nonobstructive HCM. In all cases of HCM studied, the thickness of the interventricular septum was $1.4 \mathrm{~cm}$ or more $(1.4-3.7 \mathrm{~cm})$ and the ratio of septal to left ventricular posterior wall thickness was 1.4 or more (1.4-3.2). A systolic anterior movement of the mitral valve (SAM) was observed in obstructive cases only and characterized by a large backward component in late systole and an extreme approximation to the interventricular septum at its peak.

Patients with HCM also showed abnormal echocardiographic indices of the left ventricular diastolic properties, such as the rate of diastolic descent of the mitral valve (DDR), mean diastolic posterior wall velocity (mPWVd), D/S ratio and mean rapid filling rate (mRFR). DDR correlated well with the ratio of rapid filling to total filling volume, rapid filling fraction, $(r=0.79, p<0.001)$, suggesting that reduced DDR in HCM was related with an abnormal left atrio-ventricular flow pattern.

A significant correlation was also observed between mRFR and negative maximum $\mathrm{dp} / \mathrm{dt}$ derived from the first derivative curve of the left ventricular pressure $(r=0.68, p<0.005)$. Thus echocardiography was proved to be a valuable means for investigation of the left ventricular properties during early diastole.

\section{Additional Indexing Words:}

Asymmetric septal hypertrophy Systolic anterior movement of the mitral valve Rapid filling fraction Mean rapid filling rate Negative maximum dp/dt tricular hypertrophy of unknown cause or association. The features of hypertrophic obstructive cardiomyopathy (HOCM) or idiopathic hyper-

From the Third Department of Internal Medicine, Faculty of Medicine, University of Kurume, 67 Asahi-machi, Kurume, Japan.

* Kokura National Hospital, 10 Harugaoka, Kokuraku, Kitakyushu, Japan.

Supported by Research Grant for Cardiomyopathy from the Ministry of Health and Welfare. Received for publication September 5, 1975. 
trophic subaortic stenosis (IHSS) have been described extensively because of its peculiar hemodynamics, systolic pressure gradient within the left ventricle. ${ }^{1)}$ Subsequently, it has been noted that a large number of cases, who had similar features to HOCM or IHSS, demonstrated small or no left ventricular pressure gradient. Therefore HCM is now classified roughly into 2 types, obstructive and nonobstructive. ${ }^{3 /-6), 14)}$ Functionally, both types of HCM are characterized by a diastolic failure of the left ventricle. ${ }^{2-4), 7)}$ However, the definition of nonobstructive HCM is not clear yet. In the previous study, ${ }^{51,6)}$ we classified HCM into 3 types based on the hemodynamic and left ventricular angiocardiographic features: Type I: in which therc coexisted obstruction to left ventricular outflow and the prominent hypertrophy of the interventricular septum. Type II: in which there was interventricular septal hypertrophy only without left ventricular outflow obstruction. Type III: in which there was diffuse left ventricular hypertrophy without interventricular septal hypertrophy nor outflow obstruction.

Recent advances of echocardiography presented an attractive concept for HCM. Henry et al $^{12)-14)}$ described using echocardiography that typical IHSS represent only 1 subgroup of a cardiac disease in which the characteristic anatomic abnormality is asymmetric septal hypertrophy (ASH) and left ventricular outflow obstruction is absent in most patients with ASH.

The present study was designed to assess the usefulness of echocardiography as a diagnostic method for HCM and at the same time to investigate the diastolic properties of the left ventricle.

\section{Materials ANd Methods}

Twenty-one cases, 12 men and 9 women, with hypertrophic cardiomyopathy (HCM) underwent echocardiographic examination. Their ages ranged from 16 to 56 years with a mean age of 32.0 years. The diagnosis of HCM was established in each case by a set of clinical examinations, cardiac catheterization and left ventriculogram. According to our classification of $\mathrm{HCM}_{2}{ }^{5), 6)}$ subjects were divided into 10 cases of type I (obstructive) and 11 cases of type II (nonobstructive), based on the presence or absence of the systolic pressure gradient within the left ventricle at rest. In all subjects, the left ventricular cavity in the frontal projection exhibited an inward concavity of its right inferior border during diastole. Echocardiographic and hemodynamic findings were compared in 14 cases in whom both examinations were made within 1 month. Echocardiograms obtained from 11 healthy males served as control tracings.

Echocardiographic examinations were performed using a Smith-Kline Ekoline 20 instrument with a $2.25 \mathrm{MHz}, 0.5$ inch unfocused or $7.5 \mathrm{~cm}$ focused transducer. In order to obtain clear echoes from the interventricular septum, most patients were examined in some degree of the left lateral decubitus position. Echogram of the aorta and left atrium was taken after the method of Hirata et al ${ }^{15}$ and the aortic 


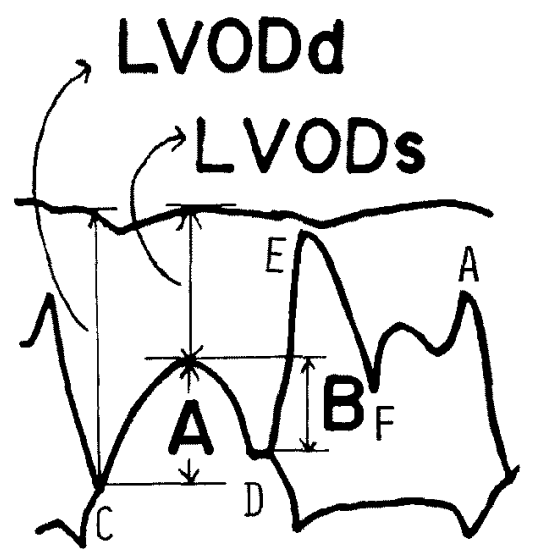

Fi.g 1. Method used to quantify the systolic anterior movement of the mitral valve (SAM).

See text for details. $A=$ early systolic anterior excursion of the mitral valve, $\mathbf{B}=$ late systalic posterior excursion of the mitral valve, $L V O D d=$ diastolic left ventricular outflow diameter, LVODs $=$ systolic left ventricular outflow diameter.

diameter (AoD) was measured at the peak of the $R$ wave of the simultaneously recorded electrocardiogram. When recording the mitral echogram, the transducer position was adjusted in order to record the posterior as well as the anterior mitral valve echoes simultaneously. The rate of early diastolic descent of the anterior mitral valve (DDR) was defined as EFo slope in the presence of an Fo point and EF slope in the absence of this point. In order to quantify the systolic anterior movement of the mitral valve (SAM), the ratio of late systolic posterior to early systolic anterior excursion (B/A ratio) was determined as shown in Fig. 1. The distance between the interventricular septum and the peak of the SAM or the midpoint of C-D in cases without SAM was measured to represent the systolic left ventricular outflow diameter (LVODs), from which LVODs/AoD ratio was calculated. The diastolic left ventricular outflow diameter (LVODd) was determined as the distance between point $C$ of the mitral valve and the ventricular septum.

Left ventricular echography was performed as described by Popp et al. ${ }^{16), 17)}$ The left ventricular diameter at end-diastole (LVDd) was measured at the peak of the $\mathrm{R}$ wave of the simultaneously recorded electrocardiogram and that at endsystole (LVDs) was taken at the point where the posterior left ventricular wall and the septum converged each other maximally. The thickness of the posterior left ventricular wall (PWT) was measured as described by Feigenbaum et al ${ }_{t}^{18}$ ) where the damping control was abruptly changed to delineate echoes from the endocardium and the pericardium-lung interface simultaneously on the same recording. The echoes from the interventricular septum were recognized by their location and characteristic motion with reference to the electrocardiogram. Echocs from the anterior and posterior surfaces of the septum were defined as almost parallel and continuous lines throughout an entire cardiac cycle and the distance between these 2 echoes was assumed to represent the thickness of the interventricular septum (IVST). IVST and PWT were measured just before atrial systole. All the above 


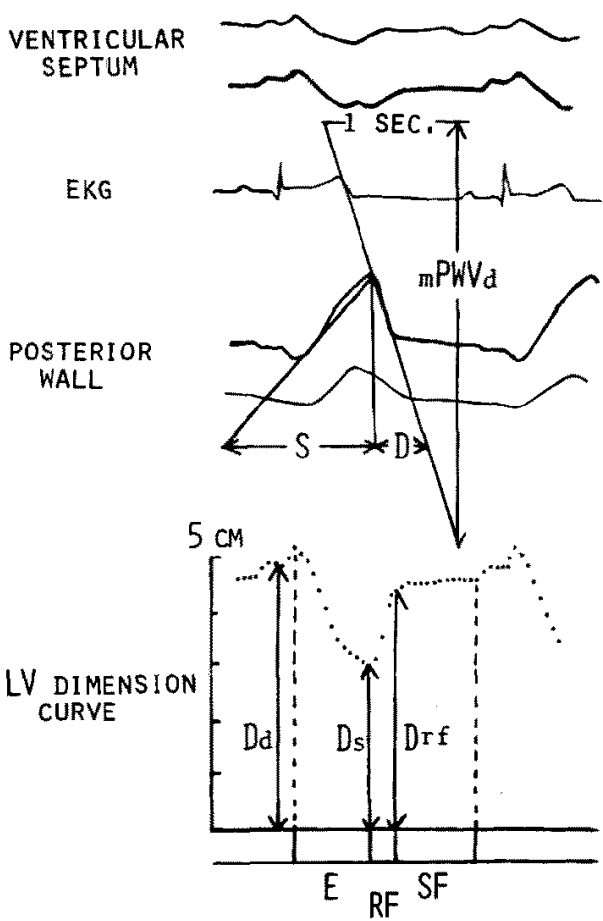

Fig. 2. Left ventricular dimension curve constructed from left ventricular echogram.

See text for details. $m P W V d=$ mean diastolic posterior wall velocity, $\mathrm{Dd}=$ left ventricular diameter at end-diastole, $\mathrm{Ds}=\mathrm{left}$ ventricular diameter at end-systole. Drf=left ventricular diameter at the end of rapid filling, $\mathrm{E}=$ ejection phase, $\mathrm{RF}=$ rapid filling phase, $\mathrm{SF}=$ slow filling phase.

measurements were made at the upstroke of echoes.

In order to investigate the diastolic properties of the left ventricle, left ventricular dimension curve was constructed manually from the left ventricular echogram as shown in Fig. 2. The onset of rapid filling (RF) was taken at the point of the initial increase of the dimension curve at the end of ventricular ejection. The end of the rapid filling phase was assumed to be the point where the rate of dimension increase abruptly reduced. Left ventricular diameter at this point was taken as that at the end of rapid filling (LVDrf). Then, mean rapid filling rate (mRFR) and rapid filling fraction (RFF) were calculated by the following equations:

$$
\begin{aligned}
& \text { mean rapid filling rate }(\mathrm{ml} / \mathrm{sec}) \\
& =\left(\mathrm{LVDr}^{3}-\mathrm{LVDs}^{3}\right) / \mathrm{rapid} \text { filling interva } \\
& \text { rapid filling fraction } \\
& \quad=\left(\mathrm{LVDrf}^{3}-\mathrm{LVDs}^{3}\right) /\left(\mathrm{LVDd}^{3}-\mathrm{LVDs}^{3}\right)
\end{aligned}
$$

In addition, mean diastolic posterior wall velocity ( $\mathrm{mPWVd}$ ) was measured as shown in Fig. 2 and D/S ratio was determined by the method of Fujino et al. ${ }^{191}$

Left ventricular pressure curve was obtained using an $8 \mathrm{~F}$ or $7 \mathrm{~F}$ dacron catheter 
and a MET 34 transducer and recorded on an 8 channel jet writing recorder (ElemaSchönander). Positive and negative maximum $\mathrm{dp} / \mathrm{dt}$ were derived from the first derivative curve of the left ventricular pressure computed continuously with a differentiating circuit. ${ }^{20)}$ Left ventriculography was performed at a rate of 6 frames/ sec. Left ventricular volumes were calculated using the area-length method of Sandler and Dodge. ${ }^{21)}$ An index of distensibility $(\mathrm{dV} / \mathrm{dP})$ of the left ventricle was calculated according to the method of Gaasch et al. ${ }^{22)}$

\section{Results}

a) Echocardiographic findings

Table I shows echocardiographic findings of 21 cases with hypertrophic

Table I. Echocardiographic Findings

\begin{tabular}{|c|c|c|c|c|}
\hline \multirow{2}{*}{ No. of Cases } & $\begin{array}{c}\text { Type I } \\
10(\mathrm{M5}, \mathrm{F5})\end{array}$ & $\begin{array}{c}\text { Type II } \\
11 \text { (M7, F4) }\end{array}$ & \multicolumn{2}{|c|}{$\begin{array}{l}\text { Control } \\
11(\mathrm{M} 11)\end{array}$} \\
\hline & Mean S.D. & Mean S.D. & Mean & S.D. \\
\hline Age (years) & $26.7 \pm 9.5$ & $36.8 \pm 11.8$ & $28.7 \pm$ & 3.4 \\
\hline $\operatorname{IVST}(\mathrm{cm}) \dagger$ & $2.3 \pm 0.5$ & $2.1 \pm 0.5$ & $1.0 \pm$ & 0.1 \\
\hline PWT $(\mathrm{cm})^{*}$ & $1.3 \pm 0.3$ & $1.1 \pm 0.2$ & $1.0 \pm$ & 0.1 \\
\hline IVST/PWT $†$ & $1.9 \pm 0.4$ & $1.9 \pm 0.6$ & $1.0 \pm$ & 0.1 \\
\hline $\operatorname{LVDd}(\mathrm{cm}) * \S$ & $4.0 \pm 0.5$ & $4.5 \pm 0.6$ & $4.8 \pm$ & 0.4 \\
\hline LVDs $(\mathrm{cm}) * \S$ & $2.3 \pm 0.6$ & $3.0 \pm 0.7$ & $3.1 \pm$ & 0.2 \\
\hline C-E Amplitude (mm) ${ }^{\dagger}$ & $21 \pm 3$ & $23 \pm 3$ & $29 \pm$ & 3 \\
\hline $\mathrm{B} / \mathrm{A} S$ & $0.74 \pm \quad 0.18$ & $0.09 \pm 0.12$ & & \\
\hline LVODs/AoDs & $0.23 \pm 0.23$ & $0.85 \pm 0.23$ & & \\
\hline LVODd/AoD* & $0.77 \pm 0.17$ & $1.03 \pm 0.24$ & $1.08 \pm$ & 0.11 \\
\hline DDR $(\mathrm{mm} / \mathrm{sec})+s$ & $34 \pm 19$ & $70 \pm 39$ & $108 \pm$ & 34 \\
\hline $\mathrm{mPWVD}(\mathrm{mm} / \mathrm{sec}) \dagger$ & $47 \pm 19$ & $49 \pm 24$ & $97 \pm$ & 17 \\
\hline $\mathrm{D} / \mathrm{S}$ ratiot & $1.16 \pm 0.45$ & $0.95 \pm 0.23$ & $0.50 \pm$ & 0.10 \\
\hline LVDrf $(\mathrm{cm}) * \S$ & $3.3 \pm 0.60$ & $4.0 \pm 0.60$ & $4.3 \pm$ & 0.30 \\
\hline RFI (sec) $\uparrow$ & $0.19 \pm 0.08$ & $0.17 \pm 0.03$ & $0.12 \pm$ & 0.03 \\
\hline mRFR $(\mathrm{ml} / \mathrm{sec}) \uparrow \mathrm{s}$ & $123 \pm 51$ & $214 \pm 85$ & $443 \pm$ & 103 \\
\hline $\mathrm{RFF} * 8$ & $0.44 \pm 0.20$ & $0.62 \pm 0.16$ & $0.65 \pm$ & 0.07 \\
\hline
\end{tabular}

values given as mean \pm standard deviation

$\uparrow$ significant difference between control and HCM (type I and type II)

* significant difference between control and type I

$\$$ significant difference between type I and type II

Abbreviations: Type I=obstructive hypertrophic cardiomyopathy, Typc II=nonobstructive hypertrophic cardiomyopathy, $M=$ male, $F=$ female, IVST = thickness of the interventricular septum, PWT $=$ thickness of the left ventricular posterior wall, LVDd=left ventricular diameter at end-diastole, $L V D s=$ left ventricular diameter at end-systole, DDR = rate of diastolic descent of the anterior mitral valve, $\mathrm{B} / \mathrm{A}=$ ratio of late systolic posterior to early systolic anterior excursion of the mitral valve, LVODs=systolic left ventricular outflow diameter, LVODd=diastolic left ventricular outflow diameter, $\mathrm{AoD}=$ aortic diameter at end-diastole, mPWVd=mean diastolic posterior wall velocity, LVDrf=left ventricular diameter at the end of rapid filling, RFI= rapid filling intcrval, $\mathrm{mRFR}=$ mean rapid filling rate, $\mathrm{RFF}=$ rapid filling fraction. 


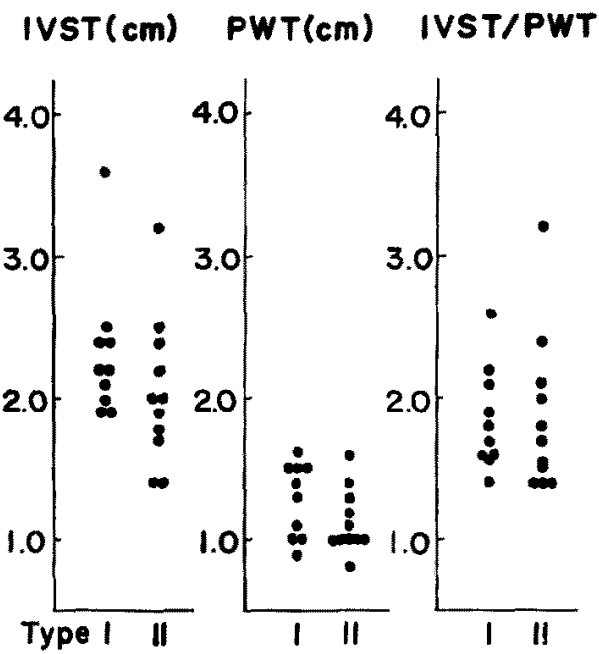

Fig. 3. Thickness of the interventricular septum (IVST) and posterior left ventricular wall (PWT) in hypertrophic cardiomyopathy (HCM).

Asymmetric septal hypertrophy was demonstrated in all cases, where the ratio of septal to posterior wall thickness (IVST/PWT) is 1.4 or greater. Type $1=$ abstructive $\mathrm{HCM}$, Type $\mathrm{I}=$ nonobstructive $\mathrm{HCM}$.

cardiomyopathy (HCM) and control subjects.

The mean thickness of the interventricular septum (IVST) was $2.3 \pm$ $0.5 \mathrm{~cm}(1.9-3.7 \mathrm{~cm})$ for cases of obstructive HCM (type I) and $2.1 \pm 0.5 \mathrm{~cm}$ $(1.4-3.2 \mathrm{~cm}$ ) for those of nonobstructive HCM (type II), being thus markedly greater than the control value of $1.0 \pm 0.1 \mathrm{~cm}$. The thickness of the left ventricular posterior wall was less marked; the posterior wall thickness (PWT) averaged $1.3 \pm 0.3 \mathrm{~cm}(0.9-1.6 \mathrm{~cm})$ for type $I, 1.1 \pm 0.2 \mathrm{~cm}(0.8-1.6 \mathrm{~cm})$ for type II, and $1.0 \pm 0.1 \mathrm{~cm}$ for controls. Consequently, the IVST $/ \mathrm{PWT}$ ratio averaged $1.9 \pm 0.4(1.4-2.6)$ for type I and $1.9 \pm 0.6(1.4-3.2)$ for type II. Thus, asymmetric septal hypertrophy (ASH) was detected in all cases studied with the IVST/PWT ratio of 1.4 or more. There was no significant difference between types I and II in IVST nor in PWT (Fig. 3).

Mean left ventricular diameter at end-diastole (LVDd) was $4.0 \pm 0.5 \mathrm{~cm}$ for type I, $4.5 \pm 0.6 \mathrm{~cm}$ for type II, and $4.8 \pm 0.4 \mathrm{~cm}$ for controls. A significant difference was noted between control and type $I(p<0.001)$.

As for mitral echograms, the systolic anterior movement of the mitral valve (SAM) was noted in all cases of type $\mathrm{I}$. The B/A ratio averaged $0.74 \pm$ $0.18(0.50-1.0)$ for type I and $0.09 \pm 0.12(0-0.29)$ for type II. Clear distinction could thus be shown between types $I$ and II in this regard $(p<0.001)$. Mean LVODs/AoD ratio was $0.23 \pm 0.23(0-0.70)$ for type $I$ and $0.85 \pm 0.23$ (0.48-1.32) for type II with the difference between the 2 types achieving 


\section{B/A LVOD\&/AOD}

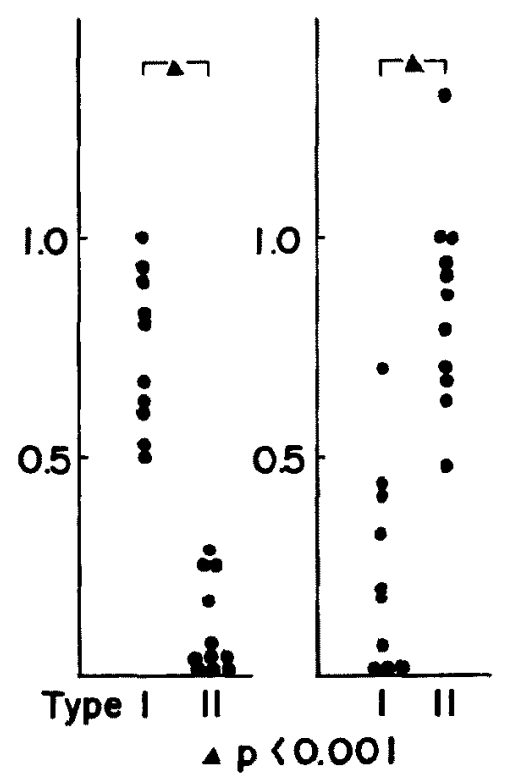

Fig. 4. B/A ratio of the systolic anterior movement (SAM) and LVODs! AoD ratio in hypertrophic cardiomyopathy (HCM).

SAM in obstructive HCM was characterized by a greater posterior excursion in late systole and by an extreme approximation to the ventricular septum at its peak. A= early systolic anterior excursion of the mitral valve, $\mathrm{B}=$ late systolic posterior excursion of the matral valve, LVODs - systolic left ventricular outflow diameter, $\mathrm{AoD}==$ aortic diameter at end-diastole, Type I = obstructive HCM, Type II= nonobstructive HCM.

statistical significance $(\mathrm{p}<0.001)$ (Fig. 4). In 3 cases of type I, the mitral valve was found to come into contact with the ventricular septum during systole. From these findings, it was considered that the SAM in type I could be characterized by a greater amplitude of posterior excursion in late systole and by an extreme approximation to the ventricular septum at its peak. Fig. 5 shows representative SAM from a patient with HCM type I.

A significant difference in LVODd/AoD ratio was noted only between type I and control $(p<0.001)$. The diastolic septum contact (i.e. contact of the anterior mitral leaflet with the ventricular septum in early diastole) was observed more frequently in type I. In 3 cases, this phenomenon was so prominent that DDR could not be measured. The $B^{\prime}-B^{\prime \prime}$ step, interruption to mitral closure, was observed in 1 case of type I and in 5 cases of type II.

Fig. 6 shows representative echocardiograms from patients of types I and II. A marked thickening of the interventricular septum is demonstrated 


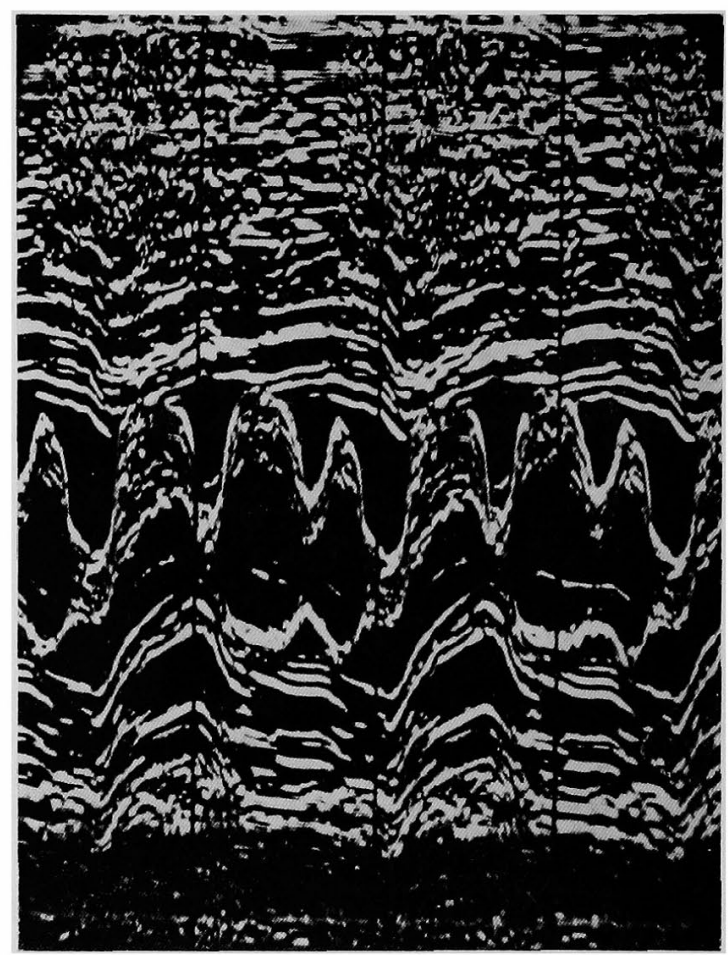

Fig. 5. Systolic anterior movement (SAM) of the mitral valve from a patient with obstructive HCM (type I).

in both cases, while large SAM is seen in a case of type I.

b) Left ventricular diastolic properties by echocardiography

The rate of diastolic descent of the anterior mitral leaflet (DDR), though unmeasurable in the aforementioned 3 cases of type $I$, averaged $34 \pm 19 \mathrm{~mm} / \mathrm{sec}$ for type I and $70 \pm 39 \mathrm{~mm} / \mathrm{sec}$ for type II, hence with a significant reduction in comparison with control value $(\mathrm{p}<0.001$ and $\mathrm{p}<0.05)$. The mean diastolic posterior wall velocity (mPWVd) was $47 \pm 19 \mathrm{~mm} / \mathrm{sec}$ in type I and $49 \pm$ $24 \mathrm{~mm} / \mathrm{sec}$ in type II. These values were significantly lower than the control value of $97 \pm 17 \mathrm{~mm} / \mathrm{sec}(\mathrm{p}<0.001)$. The $\mathrm{D} / \mathrm{S}$ ratio was $1.16 \pm 0.45$ in type $\mathrm{I}$, $0.95 \pm 0.23$ in type II, and $0.50 \pm 0.10$ in control, the difference between HCM patients and controls being statistically significant $(p<0.001)$. The mean rapid filling rate $(\mathrm{mRFR}$ ) averaged $123 \pm 51 \mathrm{ml} / \mathrm{sec}$ for type $\mathrm{I}, 214 \pm 85 \mathrm{ml} / \mathrm{sec}$ for type II, and $443 \pm 103 \mathrm{ml} / \mathrm{sec}$ for control. Here again, there was a significant reduction of $\mathrm{mRFR}$ in cases with $\mathrm{HCM}(\mathrm{p}<0.001)$. The rapid filling fraction (RFF) averaged $0.44 \pm 0.20$ for type $\mathrm{I}$, a value significantly lower than that of control $(p<0.005)$. No significant difference in RFF was noted between type II and control. 


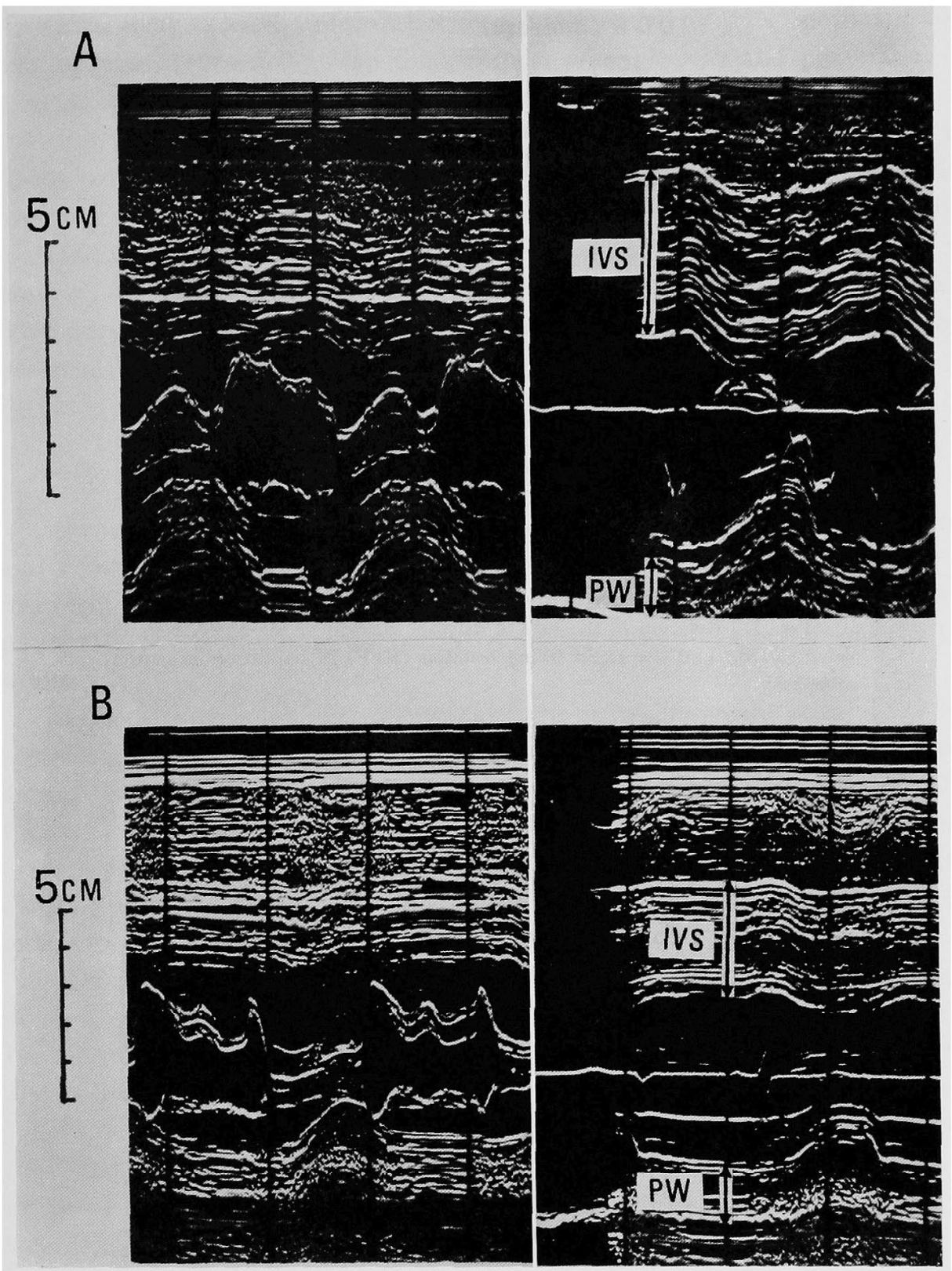

Fig. 6. Representative mitral and left ventricular echograms from a patient with obstructive HCM (A) and from a patient with nonobstructive HCM (B).

A marked thickening of the interventricular septum is shown in both cases, whereas SAM is noted in a case with obstructive HCM. IVS=interventricular septum, $\mathrm{PW}=$ posterior wall of the left ventricle. 


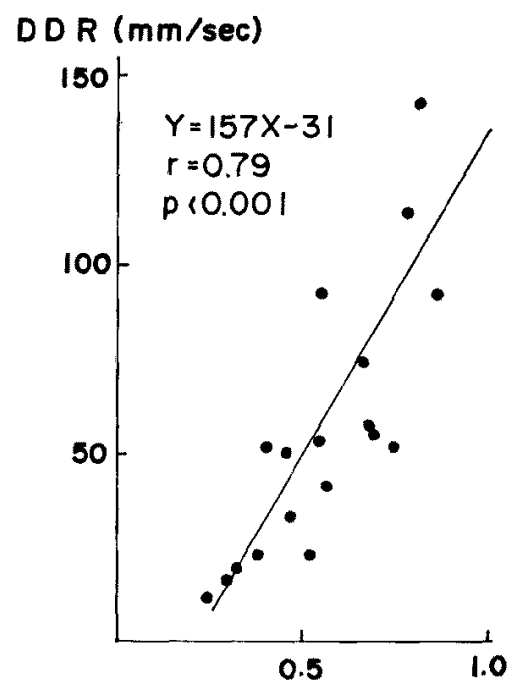

Rapid Filling Fraction

Fig. 7. Relation of the rate of diastolic descent of the anterior mitral valve (DDR) and the rapid filling fraction (RFF) in hypertrophic cardiomyopathy.

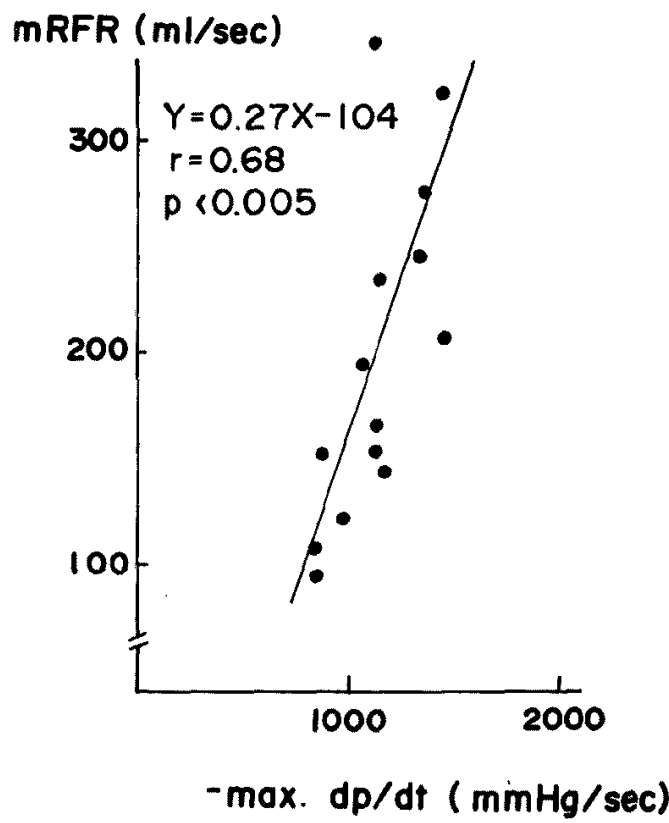

Fig. 8. Relation of the mean rapid filling rate (mRFR) and negative maximum $\mathrm{dp} / \mathrm{dt}(-\max \cdot \mathrm{dp} / \mathrm{dt})$ derived from the first derivative curve of the left ventricular pressure. 
Fig. 7 shows a relationship between DDR and RFF. A significant correlation was observed between these indices with $r=0.79$ and $p<0.001$. A correlation between DDR and D/S ratio was not significant.

Fig. 8 illustrates a relation between mRFR and negative maximum $\mathrm{dp} / \mathrm{dt}$ $(-\max \cdot \mathrm{dp} / \mathrm{dt})$ derived from the first derivative curve of the left ventricular pressure. Mean RFR correlated significantly with $-\max \cdot d p / d t \quad(r=0.68$, $\mathrm{p}<0.005)$. A correlation between $m R F R$ and the ratio of negative to positive maximum $\mathrm{dp} / \mathrm{dt}(-\max \cdot \mathrm{dp} / \mathrm{dt} /+\max \cdot \mathrm{dp} / \mathrm{dt})$ was also significant $(r=0.61, p<0.05)$. However, significant correlation was not observed between $\mathrm{mRFR}$ and $\mathrm{dV} / \mathrm{dP}$.

\section{Discussion}

Echocardiography is characterized by its ability to detect morphological and functional abnormalities of the heart noninvasively. Therefore, it is considered to be of specific value in the diagnosis of hypertrophic cardiomyopathy (HCM), a condition defined by morphological abnormalities of the left ventricle.

Echocardiographic measurements of left ventricular volumes and the left ventricular posterior wall thickness have already been investigated by many authors ${ }^{16)-18), 23)-29)}$ and known to be in good agreement with angiographic findings. As for the estimation of the interventricular septal thickness, echocardiography seems to be the only method available, except for biventricular cineangiography reported recently by Redwood et al. ${ }^{30}$ However, this measurement could not be considered as an established one. ${ }^{321}$

Despite some technical problems, echocardiography was demonstrated to be a valuable method for detection of the characteristic abnormality of HCM, asymmetric septal hypertrophy (ASH), as described by Henry et al ${ }^{12)-14)}$ and Abbasi et al. ${ }^{31}$ In all cases of HCM in the present series, IVST was $1.4 \mathrm{~cm}$ or more and the IVST/PWT ratio was 1.4 or more. These figures coincided well with those reported by Henry et al. ${ }^{12)-14)}$ However, it should be noted that cases without the deformity of the left ventricular cavity, HCM type III in our classification, ${ }^{5,6)}$ were not included in this study because of its less common occurrence and less clear clinical features. In our observation, such cases failed to exhibit echocardiographic evidence of ASH. Moreover, our previous study ${ }^{32}$ indicated that ASH was observed in some cases with hypertensive heart disease. Therefore, echocardiographic demonstration of ASH could be considered to be highly diagnostic in most cases of HCM, although the sensitivity and specificity of ASH remain to be further investigated.

Since reports by Shah et $\mathrm{al}^{(8), 10)}$ and Popp et al, ${ }^{91}$ the systolic anterior 
movement (SAM) or systolic hump of the mitral valve has been known as a specific finding of hypertrophic obstructive cardiomyopathy (HCM, type I). In our present series, a definite SAM of high amplitude was observed in cases of type I only. This was characterized by a large backward component in the late systole and an extreme approximation to the interventricular septum at its peak. Moreover, this characteristic SAM in type I could be detected with ease by the ordinary technique of the mitral echography.

In contrast, only a small late systolic posterior movement of the mitral valve was noted in 5 of 11 cases of type II. In our previous study, ${ }^{33}$ ) this small posterior movement was suggested to be a nonspecific feature, which was associated not infrequently with some conditions such as hypertensive heart disease and myocardial infarction.

However, characteristic SAM, as seen in type I, could be rarely detected in cases without pressure gradient within the left ventricle. ${ }^{33}$ Similar observation was also reported recently by Rossen et al. ${ }^{34)}$ Thus, SAM could not be considered definitely diagnostic for hypertrophic obstructive cardiomyopathy (type I).

Additional findings, that were of aid in the diagnosis of HCM, included decrease of the left ventricular and the left ventricular outflow tract diameters, the diastolic septum contact of the anterior mitral valve, reduced DDR and $\mathrm{B}^{\prime}-\mathrm{B}^{\prime \prime}$ step. These findings, however, were neither necessarily positive in all cases nor specific for HGM.

HCM is characterized hemodynamically by abnormality of left ventricular filling irrespective of the absence or presence of obstruction to left ventricular outflow. ${ }^{2)-4), 7), 35)}$ Several authors reported that echocardiography also could provide valuable indices of abnormal diastolic properties of the left ventricle. ${ }^{19), 36)-41\}}$ In the present study, patients with HCM demonstrated reduced DDR, $\mathrm{mPWVd}$ and $\mathrm{mRFR}$ and increased $\mathrm{D} / \mathrm{S}$ ratio.

Decrease of DDR has long been recognized in HCM and considered to be related mainly to the abnormal left ventricular compliance. ${ }^{81-11,42)}$ Quinones et $\mathrm{al}^{36)}$ reported a good correlation between DDR and the slope " $\mathrm{K}$ " of the left ventricular diastolic pressure-volume relation (ln $\mathrm{P}-\mathrm{V}$ relation). However, diastolic mitral valve motion is considered as reflecting the atrioventricular hemodynamic pattern unless there is no organic abnormality of the mitral valve apparatus. Therefore in this study, rapid filling fraction (RFF) was calculated and related with DDR. The outcome showed a significant correlation between these indices. Accordingly, reduced DDR in HCM was interpreted as indicating that in this pathologic condition, there is a decrease of rapid filling volume and consequently a considerable amount of the left ventricular filling takes place during the subsequent slow filling phase. 
Abnormal distensibility or compliance was thought to be concerned secondarily with reduction of DDR by affecting the left atrio-ventricular hemodynamic pattern. In some patients, however, the diastolic mitral valve motion could be of 3 peaked pattern. In such cases, it seems possible that ventricular filling occurs, to a considerable extent, during the slow filling phase without concurrent reduction of DDR.

In left ventricular echocardiographic studies, the diastolic posterior wall velocity (mean or peak) ${ }^{38), 39)}$ and $\mathrm{D} / \mathrm{S}$ ratio ${ }^{19)}$ have been investigated as significant diastolic indices. In order to study diastolic properties of the left ventricle, however, it seems more appropriate to use volume indices instead of these dimension indices. ${ }^{40)}$ Therefore, in the present study, mean rapid filling rate (mRFR) was calculated using the cube of a minor diameter of the left ventricle. Mean RFR was found significantly reduced in HGM and was also demonstrated to have good correlations with $-\max \cdot \mathrm{dp} / \mathrm{dt}$ and $-\max$. $\mathrm{dp} / \mathrm{dt} /+\max \cdot \mathrm{dp} / \mathrm{dt}$. McLaurin et $\mathrm{al}^{43)}$ noted that decrease in $-\max \cdot \mathrm{dp} / \mathrm{dt}$ was associated with ischemic changes induced by a rapid atrial pacing and that $-\max \cdot \mathrm{dp} / \mathrm{dt}$ could be a valuable index of relaxation of the left ventricular muscle. In the previous study, ${ }^{35)}$ we reported reduced $-\max \cdot \mathrm{dp} / \mathrm{dt}$ in cases with HCM. It seemed interesting that a good correlation was observed between an index of the isometric relaxation phase, $-\max \cdot \mathrm{dp} / \mathrm{dt}$, and an index of the subsequent rapid filling phase, mRFR.

Anyhow, these echocardiographic indices such as DDR, mPWVd, D/S ratio, and $m R F R$ are those of early diastole and do not seem to give a direct expression to the left ventricular distensibility and compliance, which are mainly derived from late diastolic hemodynamics. It would seem that echacardiography is rather of value as a means of studying the left ventricular properties during early diastole to which little attention has been paid before.

\section{References}

1. Braunwald E, Lambrew CT, Rockoff SD, Ross J Jr, Morrow AG: Idiopathic hypertrophic subaortic stenosis. I. A description of the disease based upon an analysis of 64 patients. Circulation 30 (Suppl 4): 3, 1964

2. Stewart S, Mason DT, Braunwald E: Impaired rate of left ventricular filling in idiopathic hypertrophic subaortic stenosis and valvular aortic stenosis. Circulation 37: 8, 1968

3. Goodwin JF: Congestive and hypertrophic cardiomyopathics. A decade of study. Lancel 1: 731,1970

4. Goodwin JF, Oakley CM: The cardiomyopathies. Brit Heart J 34: 545, 1972

5. Toshima H, Fukami T: Clinical study of idiopathic cardiomyopathy. Jap Med J 2424: 3, 1970 (in Japanese)

6. Toshima H, Fukami T: Clinical features of idiopathic hypertrophic cardiomyopathy. Jap Circulat J 35: 777, 1971 
7. Ikeda $\mathrm{H}$ : A study of the left ventricular function especially on distensibility and compliance in idiopathic cardiomyopathy. J Kurume Med Association 37: 438, 1974 (in Japanese)

8. Shah PM, Gramiak R, Kramer DH: Ultrasound location of left ventricular outflow obstruction in hypertrophic obstructive cardiomyopathy. Circulation 40: 3, 1969

9. Popp RL, Harrison DG: Ultrasound in the diagnosis and evaluation of therapy of idiopathic hypertrophic subaortic stenosis. Circulation 40:905, 1969

10. Shah PM, Gramiak R, Adelman AG, Wigle ED: Role of echocardiography in diagnostic and haemodynamic assessment of hypertrophic subaortic stenosis. Circulation 44: 891, 1971

11. Moreyra E, Klein JJ, Shimada H, Segal BL: Idiopathic hypertrophic subaortic stenosis diagnosed by reflected ultrasound. Am J Cardiol 23: 32, 1969

12. Henry WL, Clark CE, Glancy DL, Epstein SE: Echocardiographic measurement of the left ventricular outflow gradient in idiopathic hypertrophic subaortic stenosis. New Eng J Med 288: 989,1973

13. Henry WL, Clark CE, Epstein SE: Asymmetric septal hypertrophy. Echocardiographic identification of the pathognomonic anatomic abnormality of IHSS. Circulation 47: 225, 1973

14. Epstein SE, Henry WL, Glark GE, Roberts WC, Maron BJ, Ferrans VJ, Redwood DR, Morrow AG: Asymmetrical septal hypertrophy. Ann Intern Med 81 : 650, 1974

15. Hirata T, Wolfe SB, Popp RL, Helmen CH, Feigenbaum H: Estimation of left atrial size using ultrasound. Am Heart J 78: 43, 1969

16. Popp RL, Wolfe SB, Hirata $\mathrm{T}$, Feigenbaum H: Estimation of right and left ventricular size by ultrasound. A study of the echoes from the interventricular septum. Am J Cardiol 24: 523,1969

17. Popp RL, Harrison DC: Ultrasonic cardiac echography for determining stroke volume and valvular regurgitation. Circulation 41: 493, 1970

18. Feigenbaum $H_{\text {, Popp }} \mathrm{I}_{\text {, }}$, Chip JN, Haine $\mathrm{CL}$ : Left ventricular wall thickness measured by ultrasound. Arch Intern Med 121 : 391, 1968

19. Fujino T, Ito M, Kanaya S, Mashiba H, Hirata T: UCG estimation of left ventricular posterior wall motion by triangle approximation method. A preliminary report on $\mathrm{D} / \mathrm{S}$ ratio. The 24th Meeting of Jap Soc Ultrasound in Med 24: 117, 1973 (in Japanese)

20. Aoyagi M: Clinical investigation of myocardial contractility of the normal, hypertensive and hypertrophic heart by means of atrial pacing and the conventional catheterization. $\mathrm{J}$ Jap Soc Intern Med 61: 3, 1972 (in Japanese)

21. Sandler H, Dodge HT: The use of single plane angiocardiograms for the calculation of left ventricular volume in man. Am Heart J 75: 325, 1968

22. Gaasch WH, Battle WE, Oboler AA, Banas JS, Jr, Levine $\mathrm{HJ}$ : Left ventricular stress and compliance in man. With special reference to normalized ventricular function curves. Circulation 45: 746, 1972

23. Pombo JF, Troy BL, Russell RO: Left ventricular volumes and ejection fraction by echocardiography. Circulation 43: 480, 1971

24. Murray JA, Johnston W, Reid JM: Echocardiographic determination of left ventricular dimensions, volumes and performance. Am J Cardiol 30: 252, 1972

25. Feigenbaum H, Popp RL, Wolfe SB, Troy BL, Pombo JF, Haine CL, Dodge HT: Ultrasound measurements of the left ventricle. A correlative study with angiocardiography. Arch Intern Med 129: 461, 1972

26. Fortuin NJ, Hood WP, Graige $\mathbf{E}$ : Evaluation of left ventricular function by echocardiography. Circulation 46: 26, 1972

27. Feigenbaum H: Echocardiography. Lea and Febiger, Philadelphia, 1972

28. Sjogren AL, Hytonen I, Frick MH: Ultrasonic measurements of left ventricular wall thickness. Chest 57: 37, 1970

29. Troy BL, Pombo J, Rackley CE: Measurement of left ventricular wall thickness and mass by echocardiography. Circulation 45: 602, 1972 
30. Redwood DR, Scherer JL, Epstein SE: Biventricular cineangiography in the evaluation of patients with asymmetric septal hypertrophy. Circulation 49: 1116, 1974

31. Abbasi AS, MacAlpin RN, Eber LM, Pearce ML: Echocardiographic diagnosis of idiopathic hypertrophic cardiomyopathy without outflow obstruction. Circulation 46: 897, 1972

32. Toshima H, Koga Y, Yoshioka H, Akiyoshi T, Kimura N: Echocardiographic classification of hypertensive heart disease. A correlative study with clinical features. Jap Heart J 16: 377,1975

33. Shoji K, Ohkita Y, Kojyo M, Koga Y, Minagawa E, Yamada K, Toshima H, Kimura N: Abnormal systolic anterior movement of the mitral valve in various heart diseases. The 26th Meeting of Jap Soc Ultrasound in Med 26: 51, 1974 (in Japanese)

34. Rossen RM, Goodman DJ, Ingham RE, Popp RL: Echocardiographic critcria in the diagnosis of idiopathic hypertrophic subaortic stenosis. Circulation 50: 747, 1974

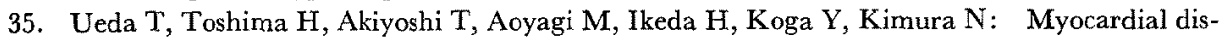
tensibility (II). Jap Circulat J 38: 603, 1974 (abstract)

36. Quinones MA, Gaasch WH, Waisser E, Alexander JK: Reduction in the rate of diastolic descent of the mitral valve echogram in patients with altered left ventricular diastolic pressurevolume relations. Circulation $49: 246,1974$

37. Konecke LL, Feigenbaum $\mathrm{H}$, Chang S, Corya BC, Fischer JG: Abnormal mitral valve motion in patients with elevated left ventricular diastolic pressures. Circulation 47: 989, 1973

38. Fogelman AM, Abbasi AS, Pearce ML, Kattus AA: Echocardiographic study of the abnormal motion of the posterior left ventricular wall during angina pectoris. Circulation 46: 905, 1972

39. Fujii J, Watanabe $\mathrm{H}$, Watanabe $\mathrm{T}$, Morita $\mathrm{K}$, Yoshimura M, Kato K: Posterior wall echogram during anginal attack and the left ventricular compliance. The 24th Meeting of Jap Soc Ultrasound in Med 24: 73, 1973 (in Japanese)

40. Gibson DG, Brown D: Measurement of instantaneous left ventricular dimension and filling rate in man, using echocardiography. Brit Heart J 35: 1141, 1973

41. Nimura Y, Nagata M, Beppu S, Tamai M, Yamada Y, Matsumoto M, Matsuo H, Abe H: Studies on an abnormal pattern of the mitral echocardiogram in cases of myocardial fibrosis and other myocardial diseases. Heart 6: 482, 1974 (in Japanese)

42. Yoshikawa T, Tanaka K, Tanaka T, Furukawa K, Kawai K, Takeuchi K, Owaki R, Kato H: Echocardiographic diagnosis of idiopathic hypertrophic subaortic stenosis. Heart 6 : 328,1974 (in Japanese)

43. McLaurin LP, Rolett EL, Grossman W: Impaired left ventricular relaxation during pacing induced ischemia. Am J Cardiol 32: 751, 1973 